\title{
Reproductive health status and related knowledge among women aged 20-39 years in rural China: a cross-sectional study
}

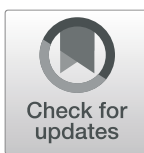

\author{
Mingzhu Chen, Yang Luo*, Jingxia Fu, Ting Wang, Yanting Meng, Chen Xu and Si Qin
}

\begin{abstract}
Background: Reproductive health is the core science of human life and is critical to the healthy and sustainable development of human society. Since 1980, China has enforced a "one child" policy. With the implementation of the Universal Two-Child Policy in 2016, every couple is allowed to have two children instead of one, which will lead to more pregnancies, births, and advanced maternal age. Thus, women aged 20-39 years, at the peak of sexual activity and fertility, will face more reproductive health problems related to pregnancies and births. This study aimed to investigate the current reproductive health status, knowledge, and factors associated with reproductive health knowledge among women aged 20-39 years in rural China.

Methods: A cross-sectional study was conducted in five villages of five cities in China. The data were collected using pre-tested and structured questionnaires through face-to-face interviews. The data were entered into Epidata version 3.0, and analyzed using SPSS version 18.0. A descriptive summary of the data and logistic regression were used to identify associated factors.

Results: One-third of the participants reported that they had suffered from gynecopathy, and 38.89\% of participants with gynecopathy-related discomfort did not seek medical treatment. Condoms and intrauterine devices were the main contraceptive measures used, and $28.70 \%$ of women had a history of induced abortion. Over half of the respondents (53.00\%) were classified as having a low reproductive health knowledge score. Factors associated with lower knowledge levels were lower education, no history of gynecopathy, and lack of acquiring knowledge from medical staff, WeChat/micro-blog, or the internet.
\end{abstract}

Conclusion: A poor reproductive health situation and low level of health knowledge were found among women aged 20-39years in rural China. More specific interventions promoting reproductive health and targeting rural women aged 20-39years are needed.

Keywords: Reproductive health status, Knowledge, Rural women, China

\section{Plain English summary}

There is an increasing concern about reproductive health problems in developing countries. With the opening of China's Universal Two-Child Policy, women aged 20-39 years, at the peak of sexual activity and fertility,

\footnotetext{
*Correspondence: ly603202@csu.edu.cn
}

Xiang Ya Nursing School, Central South University, Changsha 410013, China will face more reproductive health problems related to pregnancy, especially in less-developed rural areas.

In order to address the issue, this study investigated the reproductive health status and knowledge of women aged 20-39 years via survey and interview in rural China. Among the 973 participants, one-third had suffered from gynecopathy. Condoms and intrauterine devices were the main contraceptive measures used, and the rate of

C C The Author(s). 2020 Open Access This article is licensed under a Creative Commons Attribution 4.0 International License, which permits use, sharing, adaptation, distribution and reproduction in any medium or format, as long as you give appropriate credit to the original author(s) and the source, provide a link to the Creative Commons licence, and indicate if changes were made. The images or other third party material in this article are included in the article's Creative Commons licence, unless indicated otherwise in a credit line to the material. If material is not included in the article's Creative Commons licence and your intended use is not permitted by statutory regulation or exceeds the permitted use, you will need to obtain permission directly from the copyright holder. To view a copy of this licence, visit http://creativecommons.org/licenses/by/4.0/. The Creative Commons Public Domain Dedication waiver (http://creativecommons.org/publicdomain/zero/1.0/) applies to the data made available in this article, unless otherwise stated in a credit line to the data. 
induced abortion was $28.70 \%$. Over half of the respondents $(53.00 \%)$ had a low reproductive health knowledge score. Factors associated with lower knowledge levels were lower education, no history of gynecopathy, and lack of acquiring knowledge from medical staff, WeChat/microblog, or the internet.

In conclusion, there was a poor reproductive health situation and low level of reproductive health knowledge among women aged 20-39 years in rural China. This finding suggests that there is a need to focus on specific interventions and reproductive health education for women aged $20-39$ years in rural China.

\section{Background}

Reproductive health $(\mathrm{RH})$ is a concept first proposed by the World Health Organization (WHO) Special Programme on Human Reproductive Research in 1988 and finalized in 1994. RH refers to the physical state of the reproductive system and functions, as well as the mental and social adaptations in the reproductive process [1]. At the 4th International Conference on Population and Development in Cairo, WHO proposed the global goal of "reproductive health for all by 2015" [2], and the conference brought $\mathrm{RH}$ to the forefront of world attention. In 2010, the Outline for the Development of Chinese Women (2010-2020) mentioned "improving women's reproductive health and ensuring women's access to reproductive health technology services" as a goal of national and social development [3]. RH is a core science of human life and is critical to the healthy and sustainable development of human society [4].

Family planning has been a national priority in China since the 1970s, especially since 1980 when the "onechild" policy began. This policy restricted urban couples to one child and some rural couples, whose first child was a girl, to two children [5]. However, in 2016, the Chinese government implemented the Universal TwoChild Policy, allowing each couple to have two children. With this policy, the number of Chinese women choosing to have children may increase sharply in a short span of time, and $\mathrm{RH}$ problems related to pregnancy and childbirth will become more prominent. This is particularly significant for women aged $20-39$ years, who are in a peak sexual and reproductive period. Several studies in China have shown that women aged $20-39$ years are at high risk of sexually transmitted infections (STIs) and reproductive tract infections (RTIs), and also represent the majority of multiple abortions [6-8]. Thus, the RH of these women needs to be an area of focus.

In China, due to the privacy of $\mathrm{RH}$ and the constraints of traditional conservative ideas, rural women have little awareness of their own RH or health care. Most of them have not received RH education and have limited knowledge $[9,10]$. Health knowledge is key to enabling women to be aware of their health status and to seek appropriate health services [11]. The 2007 China State Council Working Committee on Women and Children report showed that RTI and STI rates were significantly higher in rural women than in urban women [12]. Monoarul et al. also found a wide gap in reproductive behaviors and health knowledge between urban and rural women [13].

Although some previous studies have described the $\mathrm{RH}$ status and related knowledge of women in China, the situation of rural women aged $20-39$ years is still largely unknown. The aim of this study was to investigate RH status, knowledge, and factors associated with RH knowledge among women aged 20-39years in rural China, to provide a basis for further interventions to improve RH.

On the basis of extensive literature research, our logical framework (Fig. 1) identifies RH knowledge as an outcome variable which is associated with a range of factors, including socio-demographic, sexual and reproductive behaviors, disease and treatment, knowledge sources factors $[12,14,15]$.

\section{Methods \\ Design and sample}

This cross-sectional study was conducted in Hunan Province in cooperation with the Women's Federation of Hunan Provincial Government between April 1 and August 20, 2018. Hunan Province in south-central China has a population of 68.6 million. We selected one county each in the east, west, south, north, and central areas of Hunan Province that we believed to be typical of each region, then selected one city in each county. Next, multistage cluster sampling was used to recruit samples from these five selected cities. We randomly selected one township per city, and then one village from each township, for a total of five villages. Finally, 1000 women who met the age requirement (20-39 years) were recruited.

\section{Data collection}

Investigators received training, conducted interviews with the eligible subjects, and explained the purpose and procedures of the study. The questionnaires, which were anonymous, were either completed by the subjects themselves or with the help of the investigators in cases of subjects with limited literacy.

\section{Measurements}

The investigators designed a Women's Reproductive Health Questionnaire (WRHQ) that was developed after extensive literature research and evaluated by a panel of 10 experts from Central South University, affiliated hospitals, and Hunan Women's Federation. The questionnaire contained four components, including socio-demographic 


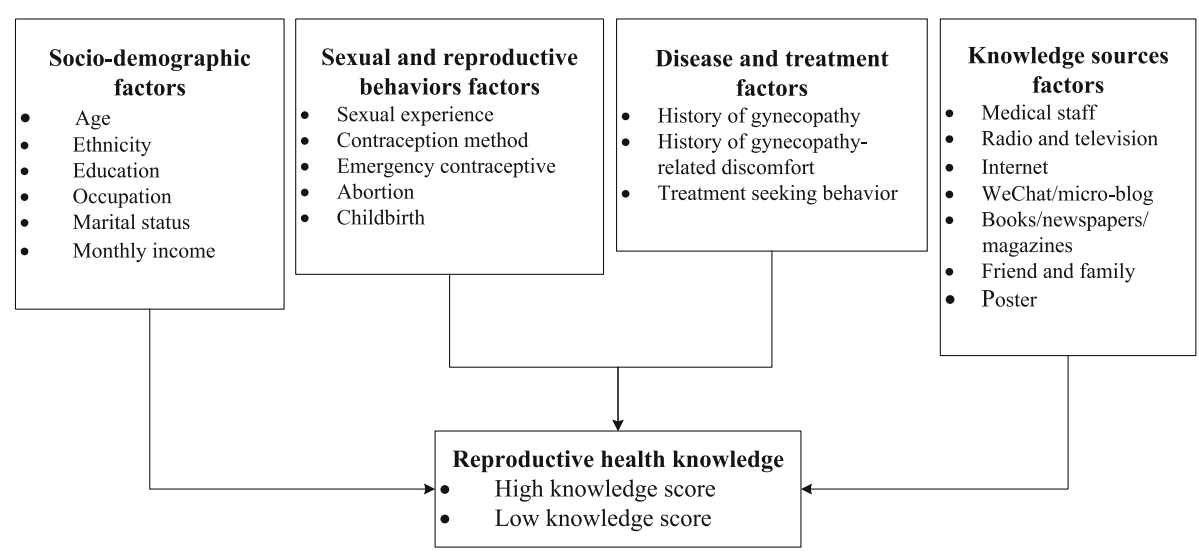

*The arrows in the figure represent only correlation

Fig. 1 A logical framework for the study of RH knowledge among women aged 20-39years in rural China

characteristics (age, ethnicity, education, occupation, marital status and average monthly household income); sexual and reproductive behaviors (sexual experience, last contraceptive methods used, emergency contraceptive use, and the number of abortions and children); gynecopathy and medical treatment (history of gynecopathy, gynecopathy-related discomfort, and treatment or reason for non-treatment); and $\mathrm{RH}$ knowledge, with a total of 30 items.

Fifteen RH knowledge questions were included in the questionnaire: three concerning RTIs and STIs, six regarding contraception and induced abortion, and six about cervical cancer and HPV vaccine. These included eight single-choice questions and seven multiple-choice questions. Each single-choice question was credited with a score of one for a correct response and zero for incorrect or indecisive responses, with a maximum single-choice question score of 8 . Due to the low rate of correct answers to multiple-choice questions, each correct option in each multiple-choice question was credited with a score of one and incorrect option with a score of zero. There were 37 total correct options for multiple-choice questions. The single and multiple-choice values were totaled to obtain a knowledge score, with a maximum score of 45 . We divided the responses into low score ( $\leq$ median score) and high score groups ( $>$ median score). In addition, participants were asked how they acquired RH knowledge.

\section{Operational definitions Induced abortion}

Induced abortion refers to the termination of pregnancy by artificial method due to unexpected pregnancy, disease and other reasons [16].

\section{Gynecopathy}

Gynecopathy refers to diseases of the female reproductive system, including diseases of the vulva, vagina, uterus, fallopian tubes and ovaries [16].

\section{Data analysis}

All data were independently double-entered and validated using EpiData (Version 3.0., The Epidata Association, Odense, Denmark). Data were analyzed with SPSS 18.0 (Version 18.0., Chicago: SPSS Inc.). Characteristics were summarized with counts (percentages) for categorical variables, and median (standard deviation, SD) for continuous variables. Both bivariate and multivariable logistic regression analyses were done to identify factors associated with RH knowledge level among rural women. Bivariate logistic regression analysis was carried out to compare RH knowledge level among different subgroups. Variables with a p-value of $<0.05$ in the bivariate analysis were further entered into the final multivariate logistic regression model. Multivariable logistic regression analysis was performed to adjust for possible confounding variables. Crude and adjusted odds ratios with their 95\% confidence intervals were calculated. The strength of the statistical association was assessed by odds ratios (OR) with $95 \%$ confidence intervals. In the multivariable analysis, a variable with a $p$-value of $<0.05$ was considered statistically significant. If more than $20 \%$ of the items had missing values, the questionnaire would be excluded as invalid.

\section{Ethical considerations}

The study was approved by the Ethical Committee of the Xiangya Nursing School, Central South University. Written consent was obtained from all respondents before the interview. 


\section{Results}

\section{Socio-demographic characteristics}

A total of 1000 women who met the entry requirements were recruited in this study, and 973 (97.3\%) participants completed the questionnaire as requested. Almost all participants (97.7\%) were ethnic Han, 86.0\% were married, and the mean age was $29.41(\mathrm{SD}=5.69)$ years. There were only $21.7 \%$ of women with college education or above. More than half (53.9\%) were farmers or workers. Average monthly household income was CNY 3000-4999 for 33.3\% and below CNY 3000 for 29.3\% (Table 1).

\section{Sexual and reproductive behaviors}

Of the 817 (84.0\%) participants with sexual experience, $68.3 \%$ were currently using contraceptives, and nearly one-third had used emergency contraceptives. Condoms $(52.0 \%)$ were the most frequently used contraception, followed by intrauterine devices (IUD, 29.9\%). More

Table 1 Socio-demographic characteristics of rural women aged 20-39 years, Hunan, China, $2018(n=973)$

\begin{tabular}{|c|c|c|}
\hline Characteristics & $n$ & $\%$ \\
\hline \multicolumn{3}{|l|}{ Age (years) } \\
\hline $20-25$ & 283 & 29.1 \\
\hline $26-30$ & 253 & 26.0 \\
\hline $31-35$ & 251 & 25.8 \\
\hline $36-39$ & 186 & 19.1 \\
\hline \multicolumn{3}{|l|}{ Ethnicity } \\
\hline Ethnic Han & 951 & 97.7 \\
\hline Ethnic minority & 9 & 0.9 \\
\hline \multicolumn{3}{|l|}{ Education } \\
\hline Senior high school or less & 749 & 77.0 \\
\hline College or more & 211 & 21.7 \\
\hline \multicolumn{3}{|l|}{ Occupation } \\
\hline Students & 49 & 5.0 \\
\hline Farmers or workers & 524 & 53.9 \\
\hline Civil servants/administrators & 29 & 3.0 \\
\hline Professional technicians & 69 & 7.1 \\
\hline Business/service personnel & 122 & 12.5 \\
\hline Unemployed & 152 & 15.6 \\
\hline \multicolumn{3}{|l|}{ Marital status } \\
\hline Married & 837 & 86.0 \\
\hline Unmarried & 135 & 13.9 \\
\hline \multicolumn{3}{|c|}{ Average monthly household income (CNY $\left.{ }^{a}\right)$} \\
\hline$<¥ 3000$ & 285 & 29.3 \\
\hline$¥ 3000-4999$ & 324 & 33.3 \\
\hline$¥ 5000-7999$ & 257 & 26.4 \\
\hline$\geq ¥ 8000$ & 98 & 9.6 \\
\hline
\end{tabular}

${ }^{\mathrm{a} C N Y: ~ C h i n e s e ~ Y u a n ; ~} 6.704$ CNY = 1 USD (14 April 2019) than $20 \%$ had a history of induced abortion and $80.1 \%$ had at least one child (Table 2).

\section{Gynecopathy and medical treatment seeking behavior} One third (33.6\%) of participants reported suffering from gynecopathy. Colpitis (inflammation of vaginal tissue or vaginitis) $(24.2 \%)$ was the most common gynecological disease. Most participants (81.5\%) reported no gynecopathyrelated discomfort in the last 2 weeks. Nearly $40 \%$ of the participants with gynecopathy-related discomfort did not seek medical treatment, primarily because they did not think it was necessary (Table 3).

\section{RH knowledge sources}

$\mathrm{RH}$ knowledge was most commonly obtained from medical staff $(59.0 \%)$ and the internet (47.9\%). Posters

Table 2 Sexual and reproductive behaviors information of rural women aged 20-39 years, Hunan, China, $2018(n=973)$

\begin{tabular}{lcc}
\hline Characteristics & $\mathrm{n}$ & $\%$ \\
\hline Having sexual experience & 817 & 84.0 \\
$\quad$ Yes & 135 & 13.9 \\
$\quad$ No & & \\
Current contraceptive use $(\boldsymbol{n}=\mathbf{8 1 7})$ & 558 & 68.3 \\
$\quad$ Yes & 271 & 33.2 \\
No & & \\
Use of emergency contraceptives $(\boldsymbol{n}=\mathbf{8 1 7})$ & 28.2 \\
Yes & 230 & 71.8 \\
No & 587 &
\end{tabular}

Contraceptive methods for the recent sexual intercourse $(n=558)$

$\begin{array}{lll}\text { Condom } & 290 & 52.0 \\ \text { Oral contraceptives (OC) } & 30 & 5.4 \\ \text { Coitus interruptus } & 31 & 5.6 \\ \text { Contraception during safe period } & 66 & 11.8 \\ \text { Intrauterine device (IUD) } & 167 & 29.9 \\ \text { Emergency contraceptives } & 6 & 1.1 \\ \text { Ligation } & 67 & 12.0 \\ \text { Contraceptive film / ointment } & 2 & 0.4 \\ \text { Rorplant } & 0 & 0.0 \\ \text { External use sperm killing agent } & 1 & 0.2\end{array}$

Number of induced abortions

$\begin{array}{lll}0 & 758 & 77.9 \\ 1 & 133 & 13.7 \\ \geq 2 & 82 & 8.4\end{array}$

Number of children

$\begin{array}{lll}0 & 194 & 19.9\end{array}$

$\begin{array}{lll}1 & 359 & 36.9\end{array}$

$\geq 2$

$420 \quad 43.2$


Table 3 Gynecopathy-related information of rural women aged 20-39 years, Hunan, China, $2018(n=973)$

\begin{tabular}{|c|c|c|}
\hline Characteristics & $\mathrm{n}$ & $\%$ \\
\hline \multicolumn{3}{|l|}{ History of gynecopathy } \\
\hline No & 646 & 66.4 \\
\hline Colpitis & 235 & 24.2 \\
\hline Cervicitis & 59 & 6.1 \\
\hline Pelvic infection & 87 & 8.9 \\
\hline Hysteromyoma/adenomyosis & 11 & 1.1 \\
\hline Oophoritic cyst & 15 & 1.5 \\
\hline Endometriosis & 1 & 0.1 \\
\hline Gynecologic tumor & 1 & 0.1 \\
\hline Pelvic floor dysfunction & 2 & 0.2 \\
\hline Abnormal menstruation & 56 & 5.8 \\
\hline Other & 4 & 0.4 \\
\hline \multicolumn{3}{|l|}{ Discomfort in the past two weeks } \\
\hline No & 793 & 81.5 \\
\hline Leucorrhea abnormality & 103 & 10.6 \\
\hline Pruritus or burning of vulva & 30 & 3.1 \\
\hline Lumbar and abdominal pain & 31 & 3.2 \\
\hline Sexual pain or vaginal bleeding & 6 & 0.6 \\
\hline Frequent urination and urgency & 20 & 2.1 \\
\hline Irregular menstruation & 53 & 5.5 \\
\hline Other & 9 & 0.9 \\
\hline \multicolumn{3}{|c|}{ Whether to seek medical assistance after discomfort $(n=180)$} \\
\hline Yes & 110 & 61.1 \\
\hline No & 70 & 38.9 \\
\hline \multicolumn{3}{|l|}{ Why not to seek medical treatment } \\
\hline It's not necessary. Just carry it. & 30 & 42.9 \\
\hline Embarrassed & 8 & 11.4 \\
\hline Self-medication & 13 & 18.6 \\
\hline To save money & 3 & 4.3 \\
\hline No effectively handled & 2 & 2.9 \\
\hline Having no time & 12 & 17.1 \\
\hline Other & 2 & 2.9 \\
\hline
\end{tabular}

(12.2\%) and books/newspapers/magazines (19.1\%) had less impact (Table 4).

\section{RH knowledge level and associated factors}

The median total score for the participants was 13.00 $(\mathrm{SD}=8.80)$ out of a maximum of 45 points. Over half $(516,53.0 \%)$ were classified as having a low RH knowledge score ( $\leq$ median score). Bivariate logistic regression was used to compare the $\mathrm{RH}$ knowledge level among the variable subgroups. There were statistically significant differences in knowledge level by education, occupation, marital status, average monthly household income, sexual
Table 4 Reproductive health $(\mathrm{RH})$ knowledge sources of rural women aged 20-39years, Hunan, China, $2018(n=973)$

\begin{tabular}{lcc}
\hline Characteristics & $\mathrm{n}$ & $\%$ \\
\hline Did you acquire knowledge from medical staff & \\
Yes & 574 & 59.0 \\
No & 386 & 39.7
\end{tabular}

Did you acquire knowledge from radio and television

$\begin{array}{lll}\text { Yes } & 285 & 29.3 \\ \text { No } & 676 & 69.5\end{array}$

Did you acquire knowledge from the internet

$\begin{array}{lll}\text { Yes } & 466 & 47.9\end{array}$

No $495 \quad 50.9$

Did you acquire knowledge from WeChat/micro-blog

$\begin{array}{lll}\text { Yes } & 346 & 35.6\end{array}$

No $615 \quad 63.2$

Did you acquire knowledge from books/newspapers/magazines

$\begin{array}{lll}\text { Yes } & 186 & 19.1 \\ \text { No } & 775 & 79.7\end{array}$

Did you acquire knowledge from friend and family

$\begin{array}{lll}\text { Yes } & 275 & 28.3 \\ \text { No } & 686 & 70.5\end{array}$

Did you acquire knowledge from poster

$\begin{array}{lll}\text { Yes } & 119 & 12.2\end{array}$

No $\quad 842 \quad 86.5$

experience, use of emergency contraceptives, number of children, history of gynecopathy, discomfort in the past 2 weeks, and acquiring knowledge from medical staff, radio and television, the internet, WeChat/micro-blog, books/ newspapers/magazines, or poster (all $p<0.05$; Table 5).

Multivariate analysis was used to identify the factors associated with RH knowledge level. RH knowledge level was a dependent variable and variables with statistical significance in the bivariate logistic regression analysis were independent variables. A low knowledge score was assigned as 1, and a high knowledge score was assigned as 0 . The multivariable regression model revealed that five variables were associated with $\mathrm{RH}$ knowledge level: education, history of gynecopathy, and acquiring knowledge from medical staff or from WeChat/micro-blog or internet (Table 5). Lower education, no history of gynecopathy, and lack of acquiring knowledge from medical staff, WeChat/micro-blog, or internet were all associated with lower RH knowledge levels (Fig. 2).

\section{Discussion}

This study suggests that there is a poor $\mathrm{RH}$ situation and low level of RH knowledge among women aged 2039 years in rural China. Factors associated with knowledge level were education, history of gynecopathy, and 
Table 5 Bivariate and multivariable logistic regression analyses for factors associated with $\mathrm{RH}$ knowledge level among rural women aged 20-39 years, Hunan, China, $2018(n=973)$

\begin{tabular}{|c|c|c|c|c|}
\hline \multirow[t]{2}{*}{ Characteristics } & \multicolumn{2}{|c|}{$\begin{array}{l}\text { RH knowledge level } \\
f(\%)\end{array}$} & \multirow[t]{2}{*}{$\begin{array}{l}\text { COR } \\
(95 \% \mathrm{Cl})\end{array}$} & \multirow[t]{2}{*}{$\begin{array}{l}\text { AOR } \\
(95 \% \mathrm{Cl})\end{array}$} \\
\hline & Low & High & & \\
\hline \multicolumn{5}{|l|}{ Education } \\
\hline Senior high school or less & $419(55.9)$ & $330(44.1)$ & $1.36(1.18-1.57)^{*}$ & $1.40(1.13-1.74)^{*}$ \\
\hline College or more & $91(43.1)$ & $120(52.9)$ & 1.0 & 1.0 \\
\hline \multicolumn{5}{|l|}{ Occupation } \\
\hline Students & $29(60.1)$ & $20(39.9)$ & $0.73(0.54-0.99)^{*}$ & $1.02(0.45-2.50)$ \\
\hline Farmers or workers & $311(59.4)$ & $213(40.7)$ & $0.57(0.40-0.82)^{*}$ & $0.65(0.42-1.01)$ \\
\hline Civil servants/administrators & $10(34.5)$ & $19(65.5)$ & $1.58(0.69-3.62)$ & $0.47(0.15-1.47)$ \\
\hline Professional technicians & $15(21.7)$ & $54(78.3)$ & $2.99(1.55-5.76)^{*}$ & $3.53(0.98-8.87)$ \\
\hline Business/service personnel & $54(44.3)$ & $68(55.7)$ & $1.05(0.65-1.69)$ & $0.85(0.47-1.52)$ \\
\hline Unemployed & $69(45.4)$ & $83(54.6)$ & 1.0 & 1.0 \\
\hline \multicolumn{5}{|l|}{ Marital status } \\
\hline Married & $427(51.0)$ & $410(49.0)$ & $0.56(0.38-0.81)^{*}$ & $0.93(0.36-2.43)$ \\
\hline Unmarried & $88(65.2)$ & $47(34.8)$ & 1.0 & 1.0 \\
\hline \multicolumn{5}{|c|}{ Average monthly household income (CNY) } \\
\hline$<¥ 3000$ & $179(62.8)$ & $106(37.2)$ & $0.41(0.26-0.65)^{*}$ & $0.81(0.43-1.52)$ \\
\hline$¥ 3000-4999$ & $159(49.1)$ & $165(50.9)$ & $0.72(0.45-1.13)$ & $1.20(0.65-2.22)$ \\
\hline$¥ 5000-7999$ & $132(51.4)$ & $125(48.6)$ & $0.65(0.41-1.05)$ & $1.11(0.59-2.08)$ \\
\hline$\geq ¥ 8000$ & $40(40.8)$ & $58(59.2)$ & 1.0 & 1.0 \\
\hline \multicolumn{5}{|l|}{ Having sexual experience } \\
\hline Yes & $410(50.2)$ & 407 (49.8) & $0.50(0.34-0.74)^{*}$ & $1.35(0.57-3.19)$ \\
\hline No & $90(66.7)$ & $45(33.3)$ & 1.0 & 1.0 \\
\hline \multicolumn{5}{|c|}{ Use of emergency contraceptives } \\
\hline Yes & $86(37.4)$ & $144(62.6)$ & $0.53(0.42-0.80)^{*}$ & $0.80(0.50-1.30)$ \\
\hline No & $430(57.9)$ & $313(42.1)$ & 1.0 & 1.0 \\
\hline \multicolumn{5}{|l|}{ Number of children } \\
\hline 0 & $124(63.9)$ & $70(36.1)$ & $0.57(0.40-0.81)^{*}$ & $0.59(0.29-1.17)$ \\
\hline 1 & $181(50.4)$ & $178(49.6)$ & $0.99(0.75-1.32)$ & $0.93(0.64-1.33)$ \\
\hline$\geq 2$ & $211(50.2)$ & 209 (49.8) & 1.0 & 1.0 \\
\hline \multicolumn{5}{|l|}{ No history of gynecopathy } \\
\hline Yes & $383(59.3)$ & $263(40.7)$ & $2.21(1.68-2.91)^{*}$ & $2.06(1.39-3.04)^{*}$ \\
\hline No & $127(39.7)$ & $193(60.3)$ & 1.0 & 1.0 \\
\hline \multicolumn{5}{|c|}{ No discomfort in the past two weeks } \\
\hline Yes & $435(54.9)$ & $358(45.2)$ & $1.63(1.17-2.28)^{*}$ & $1.49(0.92-2.41)$ \\
\hline No & $73(42.7)$ & $98(57.3)$ & 1.0 & 1.0 \\
\hline \multicolumn{5}{|c|}{ Did you acquire knowledge from medical staff } \\
\hline Yes & $243(42.3)$ & $331(57.7)$ & $0.34(0.26-0.45)^{*}$ & $0.26(0.15-0.44)^{*}$ \\
\hline No & $264(68.4)$ & $122(31.6)$ & 1.0 & 1.0 \\
\hline \multicolumn{5}{|c|}{ Did you acquire knowledge from radio and television } \\
\hline Yes & $124(43.5)$ & $161(56.5)$ & $0.59(0.45-0.78)^{*}$ & $0.90(0.52-1.81)$ \\
\hline No & $383(56.7)$ & $293(43.3)$ & 1.0 & 1.0 \\
\hline
\end{tabular}


Table 5 Bivariate and multivariable logistic regression analyses for factors associated with $\mathrm{RH}$ knowledge level among rural women aged 20-39 years, Hunan, China, 2018 ( $n=973$ ) (Continued)

\begin{tabular}{|c|c|c|c|c|}
\hline \multirow[t]{2}{*}{ Characteristics } & \multicolumn{2}{|c|}{$\begin{array}{l}\text { RH knowledge level } \\
\mathrm{f}(\%)\end{array}$} & \multirow[t]{2}{*}{$\begin{array}{l}\text { COR } \\
(95 \% \mathrm{Cl})\end{array}$} & \multirow[t]{2}{*}{$\begin{array}{l}\text { AOR } \\
(95 \% \mathrm{Cl})\end{array}$} \\
\hline & Low & High & & \\
\hline \multicolumn{5}{|c|}{ Did you acquire knowledge from internet } \\
\hline Yes & $207(44.4)$ & $259(55.6)$ & $0.52(0.40-0.67)^{*}$ & $0.50(0.30-0.83)^{*}$ \\
\hline No & $300(60.6)$ & $195(39.4)$ & 1.0 & 1.0 \\
\hline \multicolumn{5}{|c|}{ Did you acquire knowledge from WeChat/micro-blog } \\
\hline Yes & $129(37.3)$ & $217(62.7)$ & $0.37(0.28-0.49)^{*}$ & $0.26(0.15-0.45)^{*}$ \\
\hline No & $378(61.5)$ & $237(38.5)$ & 1.0 & 1.0 \\
\hline \multicolumn{5}{|c|}{ Did you acquire knowledge from books, newspapers, magazines } \\
\hline Yes & $74(39.8)$ & $112(60.2)$ & $0.52(0.38-0.72)^{*}$ & $1.04(0.52-1.68)$ \\
\hline No & $433(55.9)$ & $342(44.1)$ & 1.0 & 1.0 \\
\hline \multicolumn{5}{|c|}{ Did you acquire knowledge from poster } \\
\hline Yes & $30(25.2)$ & $89(74.8)$ & $0.26(0.17-0.40)^{*}$ & $0.63(0.41-1.02)$ \\
\hline No & $477(56.7)$ & $365(43.4)$ & 1.0 & 1.0 \\
\hline
\end{tabular}

${ }^{*} p<0.05$

*The arrows in the figure represent only correlation

acquiring knowledge by medical staff, WeChat/microblog, or the internet.

This study showed that $22.1 \%$ of women had a history of induced abortion, which is lower than the rates reported in other studies in China [9, 17]. One possible explanation is the 2016 initiation of the Universal TwoChild Policy. The prevalence of induced abortion in China is always higher than that in other developing countries $[18,19]$, possibly due to different local laws, social and cultural attitudes towards fertility control, and the roles of women in society. The legitimacy of induced abortion, the decrease of fertility intention, and misleading advertisements which lead women into thinking abortion is simple, safe, and free of complications will all cause these rates to remain high. Moreover, Zhang and $\mathrm{Wu}$ [20] have shown that a large number of induced abortions and repeat abortions in China are also due to contraceptive failure or lack of contraception.

The primary contraceptive measures reported in this research were condoms and IUDs, consistent with previous studies in China [21, 22]. Nearly $20 \%$ of participants, however, were still using coitus interruptus and safe (non-ovulation) period intercourse for contraception. The use of new effective methods, such as oral contraceptives (OC) (5.38\%) and contraceptive implants (0), was very low. Ineffective contraceptives and misuse of contraceptives both lead to contraceptive failure and increase the probability of induced abortions resulting from unwanted pregnancies. In China, basic education is deeply influenced by traditional concepts. Most educators and parents are reticent to discuss sex in physical health education, so the quality of sexual education is far

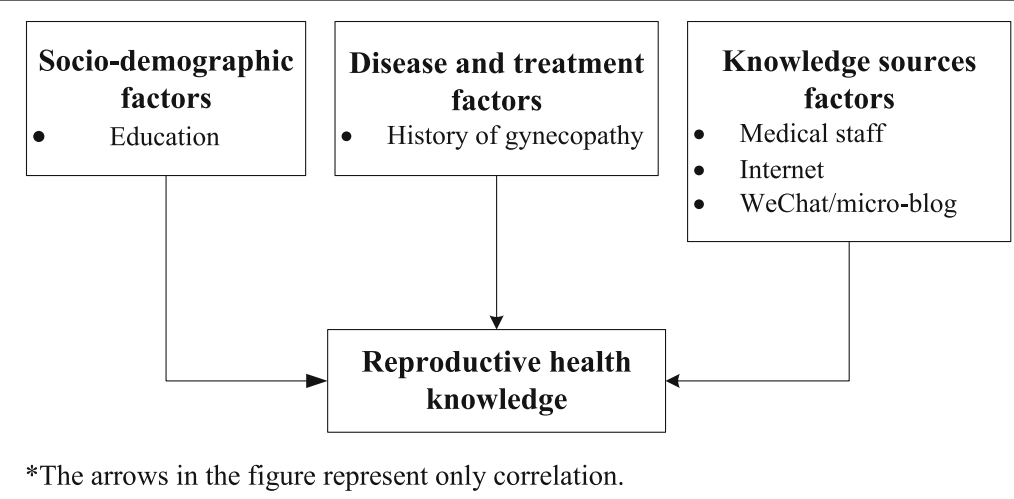

Fig. 2 Factors associated with RH knowledge level 
from adequate. Future emphasis should be placed on increasing sexual education, including contraception knowledge, from hospitals, communities, and schools.

We found that $33.61 \%$ of participants had a history of gynecopathy, which was below rates reported in other studies $[23,24]$ in rural China, especially for the prevalence of colpitis and cervicitis. In recent years, China's rural medical health has significantly improved, and a number of government projects aimed at rural women's health have achieved certain results. However, another probable reason for the discrepancy in gynecopathy rates is the information-gathering method used in this study. Self-reported status has been shown to be a poor measure of prevalence in rural China and elsewhere [14, 25], because it represents only the perceived problems. In addition, lower educational level, backward feudal ideology, and the privacy of gynecological diseases may have made our participants hide the history of gynecopathy, because they often think that gynecological diseases are related to sexual misconduct.

Our data showed that most $(81.50 \%)$ participants reported no reproductive system-related discomfort in the past 2 weeks. Among women with discomfort, 38.89\% did not seek medical treatment, primarily because they considered it unnecessary. This finding was consistent with previous studies conducted in China [26], which suggested that the healthcare use rate of rural women is low. The lack of self-care awareness caused by low education level and constraints caused by low income level contribute to the choice not to seek medical treatment. In the future, governments need to pay more attention to advertising and education, as well as free screening and treatment of common gynecological diseases for women in rural areas.

We also discovered that the $\mathrm{RH}$ knowledge level of rural women aged 20-39years was generally low, as demonstrated by the median questionnaire score of 13 points, or only $28.88 \%$ of the full score ( 45 points). The largest number of participants chose medical staff to acquire medical knowledge, followed by use of the internet. However, a previous study reported that $\mathrm{RH}$ knowledge in this population mainly came from parents, friends, and books, although the optimal source was medical staff [27]. The change in knowledge acquisition is due to the rise of township medical services and the progress of science and technology in recent years. Rural women's access to diagnosis and treatment by medical staff has greatly increased, and at the same time, the internet and mobile phones have spread to every household.

The present study indicated that lower education, no history of gynecopathy, and lack of acquiring knowledge from medical staff, WeChat/micro-blog, or the internet were associated with a worse reproductive knowledge level. Senior high school or less educated women were 1.40 times more likely to have low $\mathrm{RH}$ knowledge scores than college or more educated women. Education was also found to have a powerful and proportional influence on $\mathrm{RH}$ knowledge in other studies $[14,15]$. It is expected that less educated women are less likely to be aware of their health status and seek to improve their health knowledge. Furthermore, less educated women may have weaker decision-making power on health-related matters [14].

We found that women who had no history of gynecopathy had higher odds (2.06 times) of a lower RH knowledge level compared to women who had a positive history of gynecopathy. In agreement with our study, Liu and Zhang [15] also found that women without gynecological diseases had lower scores for $\mathrm{RH}$ knowledge than women with gynecological diseases, which may be attributed to the opportunity of women with gynecological diseases to receive relevant education from medical staff. Our findings also suggest that rural women who acquire $\mathrm{RH}$ knowledge from medical staff, WeChat/micro-blog, and the internet were all less likely to have a lower level of knowledge. Studies $[28,29]$ have shown that medical staff are the best way for women to acquire knowledge about RH. Medical staff should be encouraged to become the main providers of health education, to advertise and popularize women's health knowledge, and to improve awareness of disease symptoms. This will promote the early detection, diagnosis, and treatment of diseases, thereby improving women's overall health.

Other helpful knowledge sources in this study was the internet and social networks (WeChat/micro-blog). With the rapid development of information and communication technology, the internet and mobile phones have become the most important forms of interpersonal communication. A web-based study in rural China demonstrated that the use of a website to disseminate health information was not only feasible but that it also would be enthusiastically used by local health workers, teachers, and women's groups [30]. We should develop more targeted interventions based on these technologies to provide rural women with more comprehensive and accurate RH knowledge.

Several limitations of the study are noted. Firstly, as the data were collected through questionnaires, reporting bias cannot be excluded. Secondly, self-reporting of gynecopathy is a poor measure for investigating prevalence. Thirdly, sampling was limited to a province in south-central China and most participants were of Han ancestry. In addition, there may have been some bias in the selection of counties and cities.

However, our study sample is large, and to our knowledge, this is the first study to examine the $\mathrm{RH}$ status and related knowledge of women aged 20-39years in rural China. This study suggests that the $\mathrm{RH}$ status and 
knowledge level in this population are not optimal. Medical staff, social networks, and the internet are effective ways to provide RH knowledge to this population. This study can provide insight for future interventions to promote female RH in rural areas.

\section{Conclusion}

There are many $\mathrm{RH}$ problems in women aged 20-39 years in rural China. Although the prevalence of gynecological diseases is not high, the rate of consultation for diseases is low, induced abortion rates are high, contraceptive methods are limited and misused, and $\mathrm{RH}$ related knowledge is seriously lacking.

Specific actions should be taken to create a health service program to popularize RH knowledge, reduce ineffective contraception and induced abortion, and increase the rate of disease consultation in this population. Medical staff, the internet, and social networks (WeChat/ micro-blog) can all be effective interventions. Top-down initiatives should also be considered to monitor these efforts. Services should include health education and counseling, routine check-ups, and disease treatment to help women achieve healthy sex, pregnancies, and daily lives.

\section{Abbreviations}

$\mathrm{RH}$ : Reproductive Health; WHO: World Health Organization; STIs: Sexually Transmitted Infections; RTIs: Reproductive Tract Infections; WRHQ: Women's Reproductive Health Questionnaire; HPV: Human Papillomavirus; CNY: Chinese Yuan; USD: United States dollar; IUD: Intrauterine Devices; OC: Oral Contraceptives

\section{Acknowledgments}

We thank those who participated in this study and acknowledge the outstanding support provided by the Hunan province and local Women's Federation, Office of the Committee for Women and Children's Workers and health administration in Hunan provinces in China. We also thank Editage [www.editage.cn] for English language editing.

\section{Authors' contributions}

$M C$ and $Y L$ were involved in study conception and design. JF, TW, CX and SQ were responsible for coordinating the study. MC undertook the data collection, conducted the data analysis and drafted the manuscript. YL and YM supervised the study and reviewed the first draft manuscript. All authors read and approved the final manuscript.

\section{Funding}

This study was supported by the women's theory and practice project of Hunan Women's Federation and Research Association (Grant No. 18YB07).

\section{Availability of data and materials}

The datasets generated during the current study are available from the corresponding author on reasonable request.

\section{Ethics approval and consent to participate}

The study was approved by the Ethical Committee of the Xiangya Nursing School, Central South University. Written consent was obtained from all respondents before the interview.

\section{Consent for publication}

Not applicable.

\section{Competing interests}

We, the authors declare that we didn't have competing interests.
Received: 5 June 2019 Accepted: 29 May 2020

Published online: 10 June 2020

\section{References}

1. Glasier A, Gülmezoglu AM, Schmid GP, et al. Sexual and reproductive health 1: sexual and reproductive health: a matter of life and death. Lancet. 2019; 368(9547):1595-607.

2. The International Conference on Population and Development. Programme of action [EB/OL]. [1994-09] http://www.un.org/popin/icpd2.htm.

3. Wang R, Du JL, Luo YM, et al. The empirical research on the factors affecting reproductive health and the fertility desire among rural reproductive women-taking the area of Xiangxi for example. J Jishou Univ. 2017;05:97-101.

4. Sauer MV. Reproduction at an advanced maternal age and maternal health. Fertil Steril. 2015;103(5):1136-43.

5. Gietelbasten $\mathrm{SA}$, Jiang Q. China's family planning policies: recent reforms and future prospects. Stud Fam Plan. 2014;45(4):493-509.

6. Zhang CC. Epidemiological analysis and prevention and control strategy of venereal diseases in Liwan District of Guangzhou City from 2011 to 2015. Mod Diagn Treat. 2017;10:160-2.

7. Duo LQ. Analysis of female genital tract infection in gynecological Clinic in Grass-roots Areas. Clin Res Pract. 2016;1(7):51.

8. Yu JF, Zhao Q. Analysis of demographic characteristics of women with multiple induced abortions. Hebei Med. 2015;3:429-30.

9. Peng C. Investigation on rural Women's reproductive health and influence factors taking Xin Chong Town-Xinzhou District in Wuhan as an example. Central China Agric Univ. 2012.

10. Kaufman J, Liu Y, Fang J, et al. Improving reproductive health in rural China through participatory planning. Glob Public Health. 2012;7(8):856-68.

11. Islam MR, Thorvaldsen G. Family planning knowledge and current use of contraception among the Mruindigenous women in Bangladesh: a multivariate analysis. Open Access J Contracept. 2012;3:9-16.

12. Tang S, Tian L, Cao WW, et al. Improving reproductive health knowledge in rural China-a web-based strategy. J Health Commun. 2009;14(7):690-714.

13. Monoarul $H$, Sharmin $H$, Rumana AK, et al. A comparative study on knowledge about reproductive health among urban and rural women of Bangladesh. J Family Reprod Health. 2015;9:35-40.

14. Lu C, Xu L, Wu J, et al. Sexual and reproductive health status and related knowledge among female migrant workers in Guangzhou, China: a crosssectional survey. Eur J Obstet Gynecol Reprod Biol. 2012;160(1):60-5.

15. Liu ML, Zhang XZ, Liu TT, et al. Status and influencing factors of reproductive health knowledge among married women of childbearing age. Maternal Child Health Care China. 2017:4:22-4.

16. Xie X, Kong BH, Duan T. Obstetrics and gynecology. Peoples Med Publishing House. 2018.

17. Gao GP, Zhang RJ, Zhang XJ, et al. Prevalence and associated factors of induced abortion among rural married women: a cross-sectional survey in Anhui, China. J Obstet Gynaecol Res. 2014;41(3):383-91.

18. Bernabe OA, White PJ, Carcamo CP, et al. Clandestine induced abortion: prevalence, incidence and risk factors among women in a Latin American country. Can Med Assoc J. 2009;180(3):298-304.

19. Kant S, Srivastava R, Rai SK, et al. Induced abortion in villages of Ballabgarh HDSS: rates, trends, causes and determinants. Reprod Health. 2015;12(1):51.

20. Zhang W, Wu S, Temmerman M. Family planning needs and induced abortion in China: two cross-sectional studies. Eur J Pub Health. 2016; 26(suppl_1):73.

21. Mao L, Bai W, Huo Y, et al. Cross-sectional study of contraceptive use among Chinese women of reproductive age: results based on a mobile application (APP)-derived data. Arch Gynecol Obstet. 2018;297:1193-9.

22. Xin $Y, X D L, W u Y$, et al. Practices and knowledge of female gynecologists regarding contraceptive use: a real-world Chinese survey. Reprod Health. 2018;15(1):115.

23. Xu ZP, Han DH, Liang YJ, et al. Reproductive health in Chinese women: current status and suggestion. J Int Reprod Health/Fam Plan. 2015;34(1):53-5.

24. Li CY. Survey on reproductive health status of rural women in Kaiyuan City in 2010. Guid China Med. 2011;09:121-2.

25. Kaufman J, Yan L, Wang T, et al. A study of field-based methods for diagnosing reproductive tract infections in rural Yunnan province, China. Stud Fam Plan. 1999:30:112-20.

26. Chen $\mathrm{SH}$. Investigation of reproductive tract infections among married women of childbearing age in rural Ledu County of Qinghai Province. Chin J Fam Plan. 2008;16(9):568. 
27. Zhang JX, Zhou YL, Huang P, et al. Survey on the demand of reproductive health knowledge and medical consultation of migrant women of childbearing age. Chin Prim Health Care. 2014;28(12):55-6.

28. Zhang XF, Zhang LX. Statistical analysis of influencing factors and health education approaches of 3200 married women with common gynecological diseases. Chin Remed Clin. 2014;14(9):1216-7.

29. Nielsen A, Lan PT, Marrone $G$, et al. Reproductive tract infections in rural Vietnam, Women's knowledge, and health-seeking behavior: a crosssectional study. Health Care Women Int. 2014;1:1-20.

30. Tang L. Survey of reproductive health status of rural women. Modern Hosp. 2009:9(12):153-5.

\section{Publisher's Note}

Springer Nature remains neutral with regard to jurisdictional claims in published maps and institutional affiliations.

Ready to submit your research? Choose BMC and benefit from:

- fast, convenient online submission

- thorough peer review by experienced researchers in your field

- rapid publication on acceptance

- support for research data, including large and complex data types

- gold Open Access which fosters wider collaboration and increased citations

- maximum visibility for your research: over $100 \mathrm{M}$ website views per year

At BMC, research is always in progress.

Learn more biomedcentral.com/submissions 